\title{
PROJETO ARQUITETÔNICO PARA A CIDADE DE CATALÃO/GO: DIRETRIZES PARA A ZONA BIOCLIMÁTICA 6
}

\section{Architectural design to Catalão/GO: guidelines for Bioclimatic Zone 6}

\author{
Débora Adiane Borges ${ }^{1}$, Antover Panazzolo Sarmento ${ }^{2}$, Gabriel Bernardes de Carvalho ${ }^{3}$
}

Recebido em 19 de maio de 2017; aceito em 18 de setembro de 2017; disponível on-line em 07 de novembro de 2017.

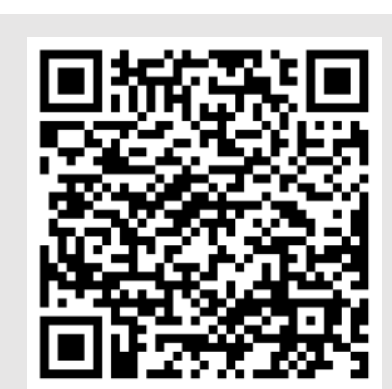

PALAVRAS CHAVE:

Bioclimatologia;

Zona Bioclimática 6;

Eficiência energética

Catalão;

Arquitetura.

\section{KEYWORDS:}

Bioclimatology;

Bioclimate zone 6;

Energy efficiency

Catalão;

Architecture.

RESUMO: O conforto dos usuários de um ambiente costuma estar atrelado a um alto consumo de energia constituindo um possível problema ambiental. A bioclimatologia é uma das táticas utilizadas para reduzir o consumo de energia com máximo conforto para os usuários através do projeto arquitetônico. Existem normas e diretrizes que especificam estratégias de desempenho térmico, entre elas, a NBR 15220 (ABNT, 2005) é uma norma brasileira que apresenta recomendações para diferentes regiões e zonas bioclimáticas do país. Além dela, existe a NBR 15575 (ABNT, 2013), a Portaria $n^{\circ} 18$ de 2012 (RTQ-R: Regulamento Técnico da Qualidade para o Nível de Eficiência Energética em Edificações Residenciais) e o Selo Casa Azul. Este trabalho avaliou as diretrizes construtivas de todas essas publicações para a Zona Bioclimática 6 (ZB6), onde se encontra a cidade de Catalão, objetivando encontrar as melhores estratégias arquitetônicas que podem ser implantadas nas casas de classe média dessa cidade. Utilizou-se o software DLN e dados do INMET para avaliação da orientação solar e dos ventos verificando as recomendações mais pertinentes para Catalão e região. Entre os resultados encontrados estão os tipos de vedações e coberturas, estratégias de condicionamento e posicionamento e dimensionamento das aberturas. A principal contribuição deste estudo foi identificar as características necessárias a um projeto arquitetônico, que atende a bioclimatologia, possibilitando maior eficiência energética para a ZB6, com destaque à cidade de Catalão.

ABSTRACT: The comfort of users of an environment is usually linked to a high energy consumption, which constitutes a true environmental problem. The bioclimatology is one strategy used to reduce energy consumption with maximum comfort to users through the architectural design. There are standard and guidelines that specify thermal performance strategies, including the NBR 15220 (ABNT, 2005) is a Brazilian standard that makes recommendations for different regions and bioclimatic zones of the country. Beyond it, there is the NBR 15575 (ABNT, 2013) Portaria $n^{\circ} .18$ of 2012 (RTQ-R: Quality Technical Regulation for Energy Efficiency of Residential Buildings in level) and the Blue House Seal. This work assessed the constructive guidelines of all these publications to the bioclimatic zone 6, where it is the city of Catalão, aiming at finding the best architectural strategies that can be deployed in middle-class houses of this city. It was used the DLN software and INMET data for evaluation of solar orientation and wind orientation looking at the most relevant recommendations to Catalão and region. Some results are the types of wall and cover, conditioning strategies and positioning and sizing of the openings. The work contributes to identify the characteristics necessary for an architectural project, which attends to bioclimatology, allowing greater energy efficiency for ZB6, with emphasis on the city of Catalão.

\footnotetext{
* Contato com os autores:

${ }^{1}$ e-mail: deboraadiane@gmail.com (D. A. Borges)

Engenheira Civil pela Universidade Federal de Goiás - Regional Catalão, DB Engenharia (64 98100-4152)

2e-mail: antoverps@gmail.com (A.P. Sarmento )

Engenheiro Agrícola, Professor Doutor do Curso de Engenharia Civil da Universidade Federal de Goiás - Regional Catalão.

${ }^{3}$ e-mail: gabrielbdec@gmail.com ( G. B. Carvalho )

Graduando em Engenharia Civil na Universidade Federal de Goiás - Regional Catalão
} 


\section{INTRODUÇÃO}

Os problemas ambientais causados pelo alto consumo de energia elétrica apresentados nas últimas décadas mostraram o risco eminente para as futuras gerações e uma das maneiras de se alcançar a eficiência energética e mitigar, uma parte, desses problemas nas edificações residenciais é por meio do projeto arquitetônico, que por se tratar de uma etapa inicial tem maiores possibilidades de intervenção. Um tema relevante dentro do contexto de sustentabilidade e da etapa de projeto é o da arquitetura bioclimática, em que se pode observar um cuidado especial com a relação entre o conforto ambiental e o consumo energético. O objetivo, nesse caso, é melhorar a qualidade de vida do ser humano no ambiente com o menor consumo de energia (DEGANI; CARDOSO, 2002; GONÇALVES; DUARTE, 2006).

Para alcançar o desempenho ambiental e a sustentabilidade é essencial incluir antes da definição do projeto arquitetônico final o estudo de: orientação solar e dos ventos; forma arquitetônica (arranjos espaciais, zoneamento e geometria dos espaços internos e externos do edifício); características do entorno imediato; materiais da estrutura e das vedações; tratamento das fachadas e coberturas conforme a necessidade de proteção solar; proporção, posicionamento e tipo das áreas envidraçadas e de abertura; detalhamento das proteções solares e das esquadrias considerando tipo e dimensão (GONÇALVES; DUARTE, 2006).

Quando esses aspectos são avaliados em conjunto, eles influenciam diretamente $\mathrm{O}$ desempenho térmico e a eficiência energética do edifício; pois, os projetos bem planejados que consideram a ventilação e iluminação natural cooperam para a realização de uma arquitetura de menor impacto ambiental ao se tratar da energia. Nesse caso, o projeto deve considerar duas etapas fundamentais: a primeira inclui conceber a arquitetura de tal modo que a demanda do edifício por energia seja reduzida; a segunda envolve a utilização dos sistemas mecânicos e elétricos mais eficientes e compatibilizados com os potenciais do projeto de arquitetura (GONÇALVES; DUARTE, 2006).

É de fundamental importância estudos que levem em consideração os vários fatores que podem gerar mais eficiência energética para os projetos arquitetônicos. Considerando que as características climáticas e materiais utilizados variam em cada região é importante fazer essa avaliação em diferentes condições. Uma vez que existem poucas pesquisas que evidenciam estratégias práticas de bioclimatologia na região sudeste do estado de Goiás, este trabalho é relevante por buscar apresentar resultados nesse sentido e tem como campo de pesquisa a cidade de Catalão, por ser um município em desenvolvimento e que possui uma das regionais da Universidade Federal de Goiás.

\section{OBJETIVO}

Este trabalho objetivou avaliar as diretrizes acerca da zona bioclimática em que a cidade de Catalão está inserida e encontrar as melhores estratégias para eficiência energética que podem ser implantadas nas casas de classe média dessa cidade. Pretendeu-se ainda, apresentar vedações, coberturas e métodos em conformidade com as preferências do cliente da região para obter maior êxito.

\section{REVISÃO TEÓRICA}

\subsection{BIOCLIMATOLOGIA}

A bioclimatologia utiliza a arquitetura e as condições favoráveis do clima, através dos seus próprios elementos e estratégias apropriadas de projeto, para melhorar as condições de conforto do homem nas edificações. Lamberts e Triana (2007) esclarecem bem seu objetivo e instrumentos, especificando que através dela se aperfeiçoam as condições interiores e exteriores a partir da interrelação do clima, do homem e do hábitat. Além disso, intenciona proporcionar uma sensação de conforto térmico aos usuários com baixo consumo de energia, utilizando-se do aproveitamento dos condicionantes climáticos que devem ser pensados 
desde o começo do processo de desenho.

0 conforto térmico que pode ser proporcionado é conhecido como "a condição da mente que expressa satisfação com o ambiente térmico" (ASHRAE 55, 2013). Uma série de estudos e observações práticas do dia a dia tem comprovado que a performance de estudantes, trabalhadores e usuários de uma edificação, no geral, é altamente afetada pelas condições ambientais, sendo que eles produzem mais em ambientes confortáveis. Além de que, se o desconforto térmico causado por frio ou calor chegar a situações extremas caracterizando o estresse térmico, ele também pode gerar problemas à saúde (LAMBERTS; XAVIER, 2002; JAMES; CHRISTIAN, 2012; HUANG et al., 2015).

A principal norma utilizada para a avaliação do conforto térmico é a ISO 7730 Ambientes térmicos moderados - Determinação dos índices PMV e PPD e especificação das condições para conforto térmico. Ela foi elaborada a partir do método desenvolvido por Fanger em 1970 que avalia as condições térmicas de um ambiente a partir de dois índices o Voto Médio Estimado (PMV - Predicted Mean Vote) e o Percentual Estimado de Insatisfeitos (PPD - Predicted Percentage of Dissatisfied). O PMV avalia o ambiente térmico baseado na avaliação de seis fatores (temperatura do ar, temperatura média radiante, velocidade do ar umidade relativa do ar, vestimenta e atividade). Ele prevê a sensação térmica média de um grande grupo de pessoas em uma escala de sete pontos, que varia de -3 (muito frio) a +3 (muito calor), e possui a faixa de conforto térmico ou neutralidade térmica entre $-0,5$ e +0,5. Enquanto o PPD é a porcentagem de pessoas insatisfeitas com 0 ambiente e está relacionado ao PMV por meio de uma equação da ISO 7730, que resulta no gráfico apresentado na Figura 1. Portanto, uma edificação apropriada deve manter esses índices de conforto térmico utilizando o mínimo possível de condicionamento artificial e o máximo de estratégias da bioclimatologia (LAMBERTS; XAVIER, 2002; GOUVÊA, 2004; ISO, 2005).

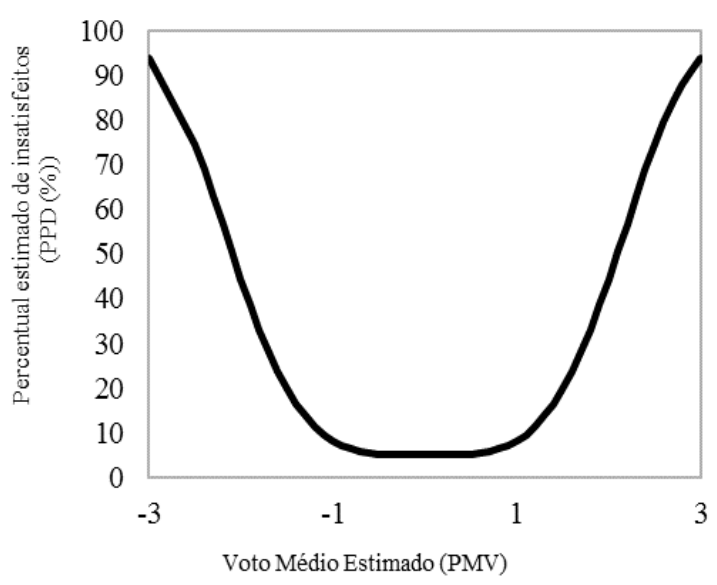

FIGURA 1: Percentual Estimado de Insatisfeitos (PPD) em função do Voto Médio Estimado (PMV). FONTE: Adaptado de ISO 7730 (2005).

Alguns países possuem o desempenho térmico como um dos requisitos mais importantes para aprovação dos projetos. Determinados aspectos bioclimáticos devem ser observados por determinarem a forma mais ou menos eficaz como o edifício responde pela influência no gasto energético, ao determinar o uso de condicionamento artificial. Esses aspectos podem ser: correta orientação solar e aos ventos dominantes do local; ventilação cruzada dentro da habitação; iluminação natural dos ambientes; tipo de materiais de construção adequados ao clima local e cores empregadas; a existência ou não de materiais isolantes na edificação em paredes e cobertura e a adoção de estratégias de projeto relacionadas ao clima (ASSIS et al., 2007; LAMBERTS; TRIANA, 2007).

No Brasil, a NBR 15220 (Desempenho térmico de edificações) foi criada para fornecer recomendações acerca de desempenho térmico de habitações unifamiliares de interesse social, na etapa de projeto, conforme as diferentes zonas bioclimáticas do país. Porquanto, as estratégias de bioclimatologia a serem utilizadas irão depender das regiões. Nessa mesma Norma é estabelecido o Zoneamento Bioclimático Brasileiro, dividido em oito zonas relativamente homogêneas quanto ao clima, como mostrado na Figura 2 (ABNT, 2005).

Para cada uma dessas zonas, são feitas recomendações técnico-construtivas que otimizam 
o desempenho térmico das edificações através de sua melhor adequação climática e são indicadas diretrizes construtivas que tratam de estratégias de projeto térmico; orientações sobre as aberturas em relação ao seu tamanho e sombreamento necessário; as vedações externas; entre outros aspectos. A Norma possui 5 partes, mas é essencialmente na Parte 3 que é instituído o Zoneamento Bioclimático Brasileiro e as diretrizes construtivas de acordo às zonas, sendo que todo esse processo é uma adaptação da Carta Bioclimática sugerida por Givoni para cada região (ABNT, 2005).

A carta bioclimática de Givoni trabalha com as variáveis: temperatura de bulbo seco e umidade relativa do ar e é um método gráfico de análise do conforto térmico. Sobre ela, é definida a zona de conforto e as demais zonas para as quais são propostas estratégias construtivas para adequar à arquitetura ao clima (LAMBERTS; TRIANA, 2007; LAMBERTS; DUTRA; PEREIRA, 2014). Para o Brasil, a NBR 15220 (ABNT, 2005) adota uma carta bioclimática adaptada, representada na Figura 3, a partir da sugerida por Givoni. A zona $E$ representa a zona de conforto onde não é necessário adotar nenhuma estratégia, e para as demais zonas são apresentadas as devidas diretrizes na Figura 3.

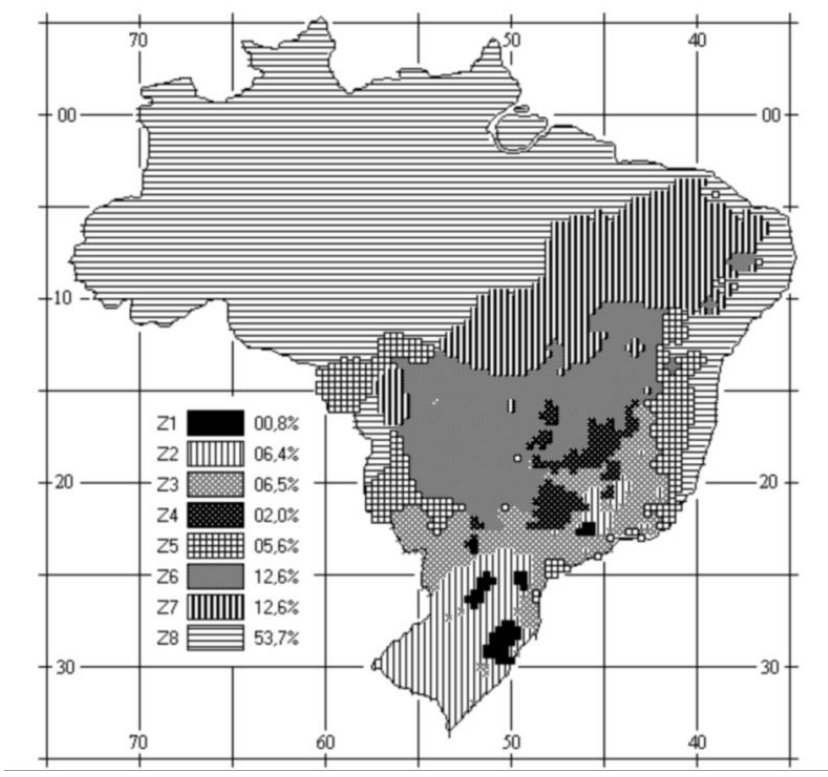

FIGURA 2: Zonas bioclimáticas brasileiras. FONTE: NBR 15220 (ABNT, 2005).

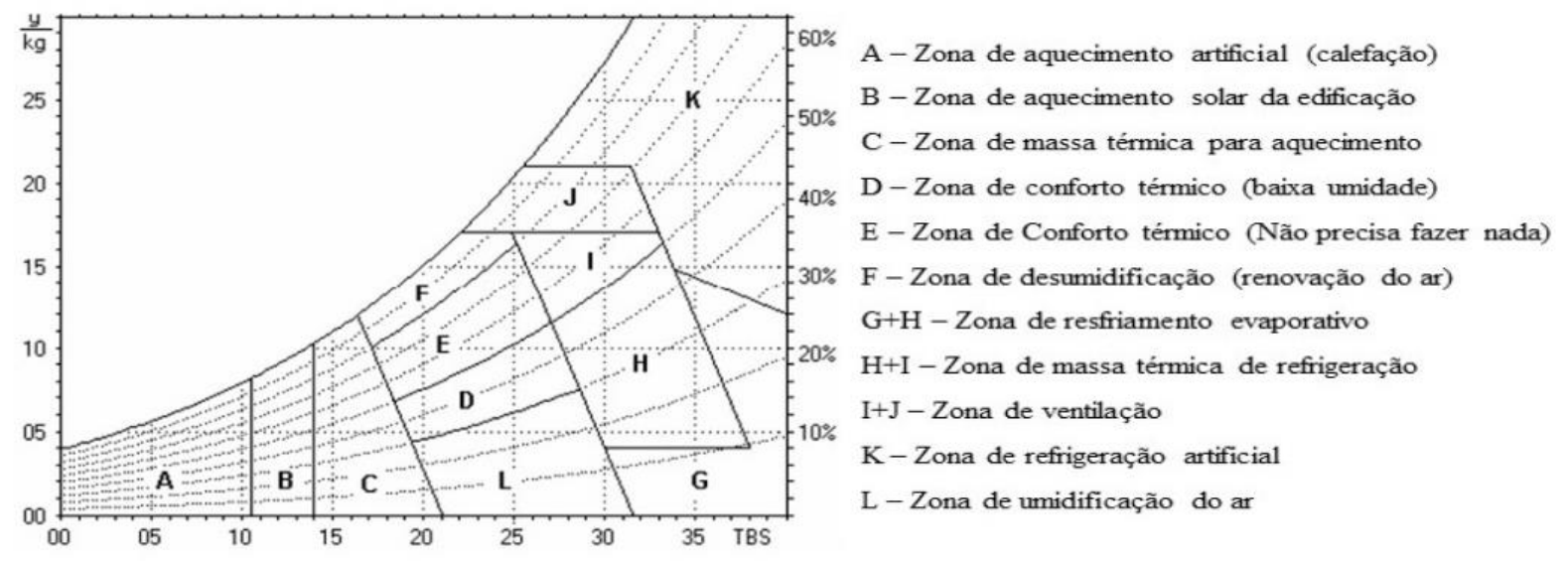

FIGURA 3: Carta bioclimática adaptada. FONTE: NBR 15220 (ABNT, 2005). 
Além da NBR 15220 (ABNT, 2005), no Brasil, existem outras normativas acerca do desempenho térmico que influem no energético, como a NBR 15575 - Edificações Habitacionais Desempenho (ABNT, 2013). Esta norma estabelece os requisitos, os critérios e os métodos para a avaliação do desempenho de sistemas de edificações habitacionais ou de seus elementos. Ela é dividida em seis partes e nas Partes 4 e 5 são apresentados os requisitos para os sistemas de vedações verticais internas e externas e para os sistemas de coberturas, respectivamente, onde são tratados inclusive sobre o desempenho térmico.

Na NBR 15575 (ABNT, 2013) está indicada a Portaria $n^{\circ} 18$, de 16 de janeiro de 2012, outra diretriz acerca de desempenho energético no Brasil. Essa portaria rege o RTQ-R (Regulamento Técnico da Qualidade para o Nível de Eficiência Energética em Edificações Residenciais) que especifica os requisitos técnicos e métodos para classificação de edificações residenciais quanto à sua eficiência energética e obtenção da Etiqueta Nacional de Conservação de Energia (ENCE) e até do Selo Procel Edificações (INMETRO, 2012; PROCEL INFO, 2015).

De forma complementar, para o projeto de uma edificação brasileira que preze pelos princípios de bioclimatologia, pode-se usar outras referências, a exemplo do Manual Selo Casa Azul (CAIXA, 2010) e do livro Eficiência Energética na Arquitetura, elaborado pelos professores Lamberts, Dutra e Pereira (2014) em convênio com a Eletrobrás Procel.

\section{MÉTODO}

Após a revisão bibliográfica que abordou a bioclimatologia de maneira geral, realizou-se uma análise da NBR 15220 (ABNT, 2005) identificando a zona bioclimática em que se insere a cidade de Catalão e as diretrizes construtivas propostas para o melhor desempenho térmico de suas edificações. Também se avaliou os critérios de desempenho da NBR 15575 (ABNT, 2013) na Parte 4: Sistemas de vedações verticais internas e externas - SVVIE e Parte 5: Requisitos para sistemas de coberturas, tal como os requisitos da Portaria $\mathrm{n}^{\circ} 18$, de 16 de janeiro de 2012 (INMETRO, 2012), e do Selo Casa Azul (CAIXA, 2010). A partir de todas as normas e literaturas avaliadas foi possível fazer um comparativo dos requisitos definindo os mais adequados para a cidade de Catalão e elucidar melhor acerca de cada uma das estratégias e conceitos abordados para a sua zona.

O segundo passo considerou que o trabalho tem por foco as estratégias para a cidade de Catalão e região, e por isso fez-se uma pesquisa de mercado em uma fábrica e fornecedora de blocos em Catalão e nas empresas de lajes para a escolha das vedações e das coberturas adequadas. Buscaram-se os tipos mais utilizados e preferíveis pelos clientes, para então, determinar as suas propriedades como transmitância térmica, capacidade térmica, atraso térmico e fator solar com base nos métodos de cálculo da Parte 2 da NBR 15220 (ABNT, 2005).

Sequentemente, considerou-se a necessidade de analisar a orientação solar e as direções predominantes dos ventos para determinação das fachadas mais adequadas para as aberturas. Em relação à orientação solar utilizou-se o auxílio do software DLN de Paulo Sérgio Scarazzato (SCARAZZATO, 1997). Na página inicial do software preencheram-se os dados iniciais da cidade de Catalão: latitude, longitude e meridiano. Na sequência, selecionou-se a estação do ano desejada e, ao clicar sobre o ícone "calcular", o programa calculou automaticamente a iluminância para todas as direções. Selecionaramse os gráficos mais críticos e necessários para a análise deste trabalho, sendo nas direções norte $\left(\mathrm{N}: 0^{\circ}\right)$, sul (S: $\left.180^{\circ}\right)$, leste $\left(\mathrm{L}: 90^{\circ}\right)$, oeste (W: $\left.270^{\circ}\right)$ e nas estações inverno e verão. Destaca-se que o programa fornece os resultados para céu claro, parcialmente nublado e encoberto e para verificar as situações mais críticas ao decorrer do ano e avaliar o melhor posicionamento da edificação, utilizaram-se os maiores valores de iluminância elaborando apenas dois gráficos, um para o verão e outro para o inverno, contendo as quatro direções principais $(\mathrm{N}, \mathrm{S}, \mathrm{L}, \mathrm{O})$ em um único gráfico para melhor análise e comparação. Quanto à orientação 
dos ventos, buscou-se no site do Instituto Nacional de Meteorologia (INMET, 2010) estudos realizados na estação 83526 (Estação meteorológica de Catalão) desde os anos de 1961, quando se iniciaram as medições nesse local, buscando as direções predominantes do vento e velocidade média ao longo de todo ano.

\section{RESULTADOS E DISCUSSÕES}

A cidade de Catalão está entre as 330 cidades brasileiras cujo clima foi classificado no Anexo A da NBR 15220 (ABNT, 2005), estando inserida na Zona Bioclimática 6 (ZB6). Logo ao avaliar a Parte 3 (Zoneamento bioclimático brasileiro e diretrizes construtivas para habitações unifamiliares de interesse social) da NBR 15220 (ABNT, 2005), encontrou-se na seção 6 as diretrizes construtivas quanto ao tamanho das aberturas para ventilação; proteção das aberturas; vedações externas (tipo de parede externa e tipo de cobertura); e estratégias de condicionamento térmico passivo para cada uma das oito zonas no país, inclusive a 6 , onde se insere Catalão.
Nos Quadros 1, 2 e 3 são expostas as diretrizes da NBR 15220 (ABNT, 2005) para essa zona.

Em relação às vedações e coberturas, elas são caracterizadas principalmente pelas propriedades: transmitância térmica (U), capacidade térmica (CT) e absortância solar $(\alpha)$. A transmitância térmica está relacionada à permissão de passagem de energia sendo definida pelo INMETRO (2012) como a transmissão de calor em unidade de tempo e através de uma área unitária de um elemento construtivo, podendo ser calculada através do método apresentado na Parte 2 da NBR 15220 (ABNT, 2005), a sua unidade é $\left[\mathrm{W} /\left(\mathrm{m}^{2} . \mathrm{K}\right)\right]$. A capacidade térmica é a quantidade de calor necessária para variar em uma unidade a temperatura de um sistema tendo como unidade básica $\left[\mathrm{kJ} /\left(\mathrm{m}^{2} . \mathrm{K}\right)\right]$. Já a absortância solar é a razão entre a taxa de radiação solar absorvida por uma superfície e a taxa de radiação solar que incide sobre esta mesma superfície, sendo adimensional e dada em função da cor (ABNT, 2005; KAPPAUN, 2012; INMETRO, 2012). Os requisitos dessas propriedades para a ZB6 são apresentados no Quadro 4.

QUADRO 1: Aberturas para ventilação e sombreamento das aberturas para a ZB6.

\begin{tabular}{|c|c|}
\hline Aberturas para ventilação & Sombreamento das aberturas \\
\hline Médias & Sombrear aberturas \\
\hline
\end{tabular}

FONTE: NBR 15220 (ABNT, 2005).

\begin{tabular}{|c|}
\hline QUADRO 2: Tipos de vedações externas para a ZB6. \\
\hline Vedações externas \\
\hline Parede: Pesada \\
\hline Cobertura: Leve isolada \\
\hline
\end{tabular}

FONTE: NBR 15220 (ABNT, 2005).

\begin{tabular}{|c|r|}
\hline \multicolumn{2}{|c|}{ QUADRO 3: Estratégias de condicionamento térmico passivo para a ZB6. } \\
\hline Estação & Sombreamento das abeturas \\
\hline \multirow{2}{*}{ Verão } & H) Resfriamento evaporativo e massa térmica para resfriamento \\
\cline { 2 - 3 } & J) Ventilação seletiva (nos períodos quentes em que a temperatura interna seja superior à externa) \\
\hline Inverno & C) Vedações internas pesadas (inércia térmica) \\
\hline Nota: Os códigos H, J e C são os mesmos adotados na metodologia utilizada para definir o Zoneamento Bioclimático \\
do Brasil (Anexo B da NBR 15220).
\end{tabular}


A NBR 15220 (ABNT, 2005) ainda apresenta em seus requisitos duas outras propriedades: Atraso térmico ( $\varphi$ - Horas) e Fator Solar (FSo - \%). O atraso térmico é o tempo que decorre para que a variação térmica de um meio seja manifestada na superfície oposta de um componente construtivo em contato com esse meio e submetido a um regime periódico de transmissão de calor. E o fator solar, nesse caso de elementos opacos, é a razão entre a taxa de radiação solar que é transmitida por um componente opaco e a taxa da radiação solar total que incide sobre a superfície externa dele. Seus valores limites também estão apresentados no Quadro 4.

Vale ressaltar que ao se analisarem as diretrizes da NBR 15220 (ABNT, 2005), NBR 15575 (ABNT, 2013), RTQ-R (Portaria $\mathrm{n}^{\circ}$ 18, de 16 de janeiro de 2012) (INMETRO, 2012) e do Selo Casa Azul (CAIXA, 2010) percebeu-se algumas divergências nos requisitos apresentados e no Quadro 4 são apresentados os diferentes valores. Ao analisar o Quadro 4 percebe-se que adotando $\mathrm{U} \leq 2,20 \mathrm{~W} /\left(\mathrm{m}^{2} . \mathrm{K}\right) ; \mathrm{CT} \geq 130 \mathrm{~kJ} /\left(\mathrm{m}^{2} . \mathrm{K}\right)$; $\varphi \geq 6,5$ h e FSo $\leq 3,5 \%$ para as vedações e $U \leq 1,50$ $\mathrm{W} /\left(\mathrm{m}^{2} . \mathrm{K}\right)$ para $\alpha>0,6 ; \mathrm{U} \leq 2,00 \mathrm{~W} /\left(\mathrm{m}^{2} . \mathrm{K}\right)$ para $\alpha \leq 0,6$; $\varphi \leq 3,3 \mathrm{~h}$ e FSo $\leq 6,5 \%$ para as coberturas os critérios estariam atendidos para todas as normativas.

O Anexo V da Portaria $n^{\circ} 50$ (INMETRO, 2013) e o Anexo D da Parte 3 da NBR 15220 (ABNT, 2005) apresentam as propriedades térmicas de algumas paredes e coberturas. Entre elas, encontrou-se um modelo de vedação (Figura 4) que poderia satisfazer as principais condições necessárias para a ZB6. Todavia em contato com uma fábrica e fornecedora de blocos cerâmicos de Catalão, obteve-se a informação que o principal bloco vendido nos anos de 2014 e 2015 é o de

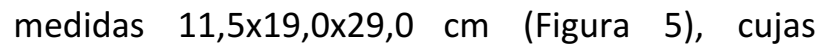
propriedades não são as apresentadas. Logo, seguindo os procedimentos da NBR 15220 (ABNT, 2005) e os valores de referência de cálculo comuns para a cidade de Catalão, calculou-se as propriedades para esse bloco calculadas conforme o método de cálculo da Parte 2 da NBR 15220 (ABNT, 2005) e apresentadas na Tabela 1.

QUADRO 4: Quadro de pré-requisitos de vedações e coberturas conforme várias normativas brasileiras para a ZB6.

\begin{tabular}{|c|c|c|c|c|c|c|}
\hline Normativa & Componente & $\begin{array}{c}\text { Absortância } \\
\text { solar }(\alpha) \\
\text { [adimensi } \\
\text { onal] }\end{array}$ & $\begin{array}{c}\text { Transmitância } \\
\text { térmica } \\
\text { (U) }\left[\mathrm{W} /\left(\mathrm{m}^{2} \cdot \mathrm{K}\right)\right]\end{array}$ & $\begin{array}{l}\text { Capacidade } \\
\text { térmica } \\
(\mathrm{CT}) \\
{\left[\mathrm{kJ} /\left(\mathrm{m}^{2} . \mathrm{K}\right)\right]}\end{array}$ & $\begin{array}{c}\text { Atraso } \\
\text { térmico ( } \phi) \\
\text { [horas] }\end{array}$ & $\begin{array}{l}\text { Fator Solar - } \\
\text { (FSo) } \\
{[\%]}\end{array}$ \\
\hline \multirow{2}{*}{$\begin{array}{c}\text { NBR } 15220 \\
\text { (ABNT, } \\
\text { 2005) }\end{array}$} & Vedação & \multirow[b]{2}{*}{ S/ exigência } & $U \leq 2,20$ & \multirow[b]{2}{*}{ S/ exigência } & $\phi \geq 6,5$ & FSo $\leq 3,5$ \\
\hline & Cobertura & & $U \leq 2,00$ & & $\phi \leq 3,3$ & FSo $\leq 6,5$ \\
\hline \multirow{4}{*}{$\begin{array}{c}\text { NBR } 15575 \\
\text { (ABNT, } \\
2013)\end{array}$} & \multirow{2}{*}{ Vedação } & $\alpha \leq 0,6$ & $U \leq 3,70$ & $\mathrm{CT} \geq 130$ & \multirow{4}{*}{ S/ exigência } & \multirow{4}{*}{ S/ exigência } \\
\hline & & $\alpha \leq 0,6$ & $U \leq 2,50$ & $\mathrm{CT} \geq 130$ & & \\
\hline & \multirow{2}{*}{ Cobertura } & $\alpha \leq 0,6$ & $U \leq 2,30$ & \multirow{2}{*}{ S/ exigência } & & \\
\hline & & $\alpha \leq 0,6$ & $U \leq 1,50$ & & & \\
\hline \multirow{4}{*}{$\begin{array}{c}\text { RTQ-R } \\
\text { (INMETRO, } \\
\text { 2012) }\end{array}$} & \multirow{2}{*}{ Vedação } & $\alpha \leq 0,6$ & $U \leq 3,70$ & $\mathrm{CT} \geq 130$ & \multirow{4}{*}{ S/ exigência } & \multirow{4}{*}{ S/ exigência } \\
\hline & & $\alpha \leq 0,6$ & $U \leq 2,50$ & $C T \geq 130$ & & \\
\hline & \multirow{2}{*}{ Cobertura } & $\alpha \leq 0,6$ & $\mathrm{U} \leq 2,30$ & \multirow{2}{*}{ S/ exigência } & & \\
\hline & & $\alpha \leq 0,6$ & $\mathrm{U} \leq 1,50$ & & & \\
\hline \multirow{4}{*}{$\begin{array}{c}\text { Selo Casa } \\
\text { Azul } \\
\text { (CAIXA, } \\
\text { 2010) }\end{array}$} & \multirow{2}{*}{ Vedação } & $\alpha \leq 0,6$ & $U \leq 3,70$ & $\mathrm{CT} \geq 130$ & \multirow{4}{*}{ S/ exigência } & \multirow{4}{*}{ S/ exigência } \\
\hline & & $\alpha \leq 0,6$ & $\mathrm{U} \leq 2,50$ & $\mathrm{CT} \geq 130$ & & \\
\hline & \multirow{2}{*}{ Cobertura } & $\alpha \leq 0,6$ & $U \leq 2,30$ & \multirow{2}{*}{ S/ exigência } & & \\
\hline & & $\alpha \leq 0,6$ & $U \leq 1,50$ & & & \\
\hline
\end{tabular}




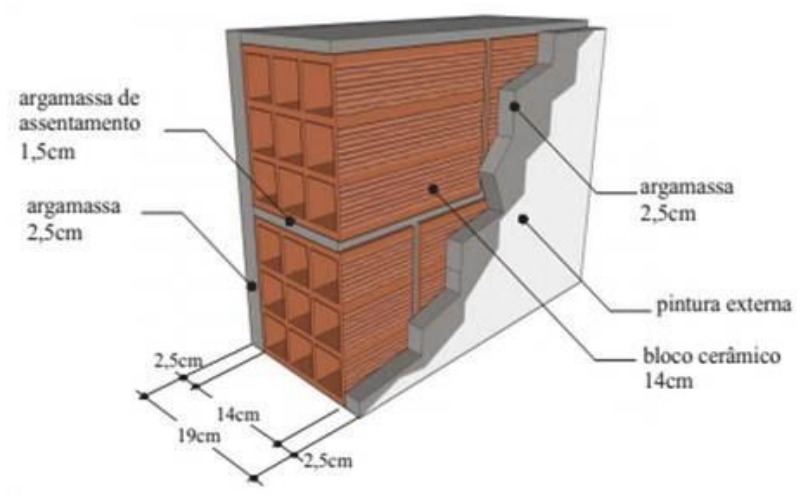

Descrição:

Argamassa interna $(2,5 \mathrm{~cm})$

Bloco cerâmico $(14,0 \times 19,0 \times 29,0 \mathrm{~cm})$

Argamassa externa $(2,5 \mathrm{~cm})$

Pintura externa $(\alpha)$

\begin{tabular}{c|c}
\hline$U$ & $C_{T}$ \\
\hline$\left[\mathrm{W} /\left(\mathrm{m}^{2} \mathrm{~K}\right)\right]$ & {$\left[\mathrm{k} / \mathrm{m}^{2} \mathrm{~K}\right]$} \\
\hline 1,85 & 161
\end{tabular}

FIGURA 4: Descrição e propriedades de modelo de parede adequado para a ZB6 com bloco 14,0x19,0×29,0cm. FONTE: INMETRO (2012).

\section{TABELA 1: Propriedades térmicas do bloco cerâmico comum à cidade de Catalão.}

\begin{tabular}{|c|c|c|c|c|c|}
\hline Largura do tijolo & 0,1150 & $\mathrm{~m}$ & \multirow{3}{*}{$\begin{array}{c}\text { Revestimento } \\
\text { argamassado e } \\
\text { argamassa de } \\
\text { assentamento }\end{array}$} & $\rho_{\text {argamassa }}$ & 1950 \\
\hline Altura do tijolo & 0,1900 & $\mathrm{~m}$ & & \begin{tabular}{|l|} 
cargamassa $_{\text {a }}$ \\
\end{tabular} & 1,00 \\
\hline Comprimento do tijolo & 0,2900 & $\mathrm{~m}$ & & $\lambda_{\text {argamassa }}$ & 1,15 \\
\hline Espessura furo horizontal & 0,0410 & $\mathrm{~m}$ & \multirow{3}{*}{ Bloco cerâmico (tijolo) } & $\rho_{\text {cerâmica }}$ & 1150 \\
\hline Espessura furo vertical & 0,0370 & $\mathrm{~m}$ & & $\mathrm{c}_{\text {cerâmica }}$ & 0,92 \\
\hline Espessura revestimento de argamassa & 0,0250 & $\mathrm{~m}$ & & $\lambda_{\text {cerâmica }}$ & 0,70 \\
\hline Espessura argamassa de assentamento & 0,0150 & $\mathrm{~m}$ & $\mathrm{R}_{\mathrm{ar}}$ & 0,16 & $\left(\mathrm{~m}^{2} \cdot \mathrm{K}\right) / \mathrm{W}$ \\
\hline Espessura espaço entre furos Horizontal & 0,0110 & $\mathrm{~m}$ & $\mathrm{R}_{\mathrm{si}}$ & 0,13 & $\left(\mathrm{~m}^{2} \cdot \mathrm{K}\right) / \mathrm{W}$ \\
\hline Espessura espaço entre furos Vertical & 0,0084 & $\mathrm{~m}$ & $\mathrm{R}_{\mathrm{se}}$ & 0,04 & $\left(\mathrm{~m}^{2} \cdot \mathrm{K}\right) / \mathrm{W}$ \\
\hline Quantidade de furos horizontal & 2 & un. & \multirow{2}{*}{$\alpha$} & \multirow{2}{*}{0,3} & \multirow{2}{*}{$\begin{array}{c}\text { Amarela } \\
\text { ou mais } \\
\text { clara }\end{array}$} \\
\hline Quantidade de furos vertical & 4 & un. & & & \\
\hline $\mathrm{Aa}$ & 0,0074 & & & & \\
\hline $\mathrm{Ab}$ & 0,0024 & & & & \\
\hline Ac & 0,0107 & & & & \\
\hline $\mathrm{Ra}$ & 0,14 & & & & \\
\hline $\mathrm{Rb}$ & 0,21 & & & & \\
\hline $\mathrm{Rc}$ & 0,41 & & & & \\
\hline $\mathrm{Rt}$ & 0,29 & & & & \\
\hline RT & 0,46 & & & & \\
\hline $\mathrm{U}$ & 2,17 & & & & \\
\hline $\mathrm{Ca}$ & 321,75 & & & & \\
\hline $\mathrm{Cb}$ & 219,17 & & & & \\
\hline $\mathrm{Cc}$ & 132,41 & & & & \\
\hline $\mathrm{CT}$ & 155 & & & & \\
\hline$\phi$ & 3,64 & Horas & & & \\
\hline Fso & 2,60 & $\%$ & & & \\
\hline
\end{tabular}

FONTE: Autoria própria (2016)

Conforme se percebe na Tabela 1, o valor de $\mathrm{U}$ igual a $2,17 \mathrm{~W} /\left(\mathrm{m}^{2} . \mathrm{K}\right)$ e $\mathrm{CT}$ de $155 \mathrm{~kJ} /\left(\mathrm{m}^{2} . \mathrm{K}\right)$ satisfazem as condições $U \leq 2,20 \mathrm{~W} /\left(\mathrm{m}^{2} . \mathrm{K}\right)$ e $\mathrm{CT} \geq 130 \mathrm{~kJ} /\left(\mathrm{m}^{2} . \mathrm{K}\right)$, respectivamente. Considerando parede amarela ou mais clara, cujo $\alpha$ é igual ou menor que 0,3 ; o FSo é igual ou menor que 2,60\% satisfazendo a condição de FSo $\leq 3,5 \%$. Logo, o único valor que não atingiu as recomendações da norma para o bloco de $11,5 \times 19,0 \times 29,0 \mathrm{~cm}$ foi o atraso térmico, que resultou em 3,64 horas, enquanto $\circ$ recomendado era $\varphi \geq 6,5$. Apesar disso, decidiu-se pela adoção dessa vedação, apresentada na Figura 5; porquanto, a parede de $14,0 \times 19,0 \times 29,0 \mathrm{~cm}$ apresentada na Figura 4 também não atenderia ao atraso térmico recomendado, sendo igual a 3,72 horas. Uma alternativa seria a utilização de paredes duplas, o que não tem aceitação no mercado de Catalão. E o 
objetivo do projeto em questão, vai além de propor uma edificação sustentável, englobando a aprovação dos clientes catalanos e custo acessível à classe média. Além disso, só há exigência quanto ao $\varphi$ na NBR 15220 (ABNT, 2005).

Um modelo de cobertura considerado aplicável à cidade de Catalão é encontrado no Anexo V da Portaria $n^{\circ} 50 / 2013$, como visto na Figura 6. Vale ressaltar que o modelo de cobertura ultrapassa um pouco o valor máximo de $U$ de $1,50 \mathrm{~W} /\left(\mathrm{m}^{2} . \mathrm{K}\right)$, sendo $1,52 \mathrm{~W} /\left(\mathrm{m}^{2} . \mathrm{K}\right)$. Todavia, considerou-se aceitável porque esse valor de 1,50 é o mais exigente possível de todas as normas e a diferença entre os valores de 1,52 e 1,50 é inferior a 1,5\%, sendo aceitável pela própria NBR 15220 (ABNT, 2005).

Todavia, as empresas de projeto e fabricação de lajes e coberturas, especificaram que o tipo mais utilizado em Catalão para casas de classe média são lajes pré-moldadas TG-8, com preenchimento de lajotas cerâmicas ou EPS, capa de concreto de $4 \mathrm{~cm}$, argamassa de $1 \mathrm{~cm} \mathrm{e}$ telhas de concreto. E ainda esclarecem que quando o cliente se preocupa com o conforto térmico ele prefere o EPS, que é um isolante térmico, e suas principais medidas são 1,00 x 0,40 x 0,08 m. Logo, na Tabela 2 são apresentadas as propriedades para esse tipo de cobertura calculadas conforme o método de cálculo da Parte 2 da NBR 15220 (ABNT, 2005). Ressalta-se que devido à predominância de clima quente na região, na Tabela 2 são apresentados os cálculos para a situação de verão.

Conforme se percebe na Tabela 2, o valor de $\mathrm{U}$ igual a $1,06 \mathrm{~W} /\left(\mathrm{m}^{2} . \mathrm{K}\right)$ e de FSo igual a $3,07 \%$ satisfazem as condições $U \leq 1,50 \mathrm{~W} /\left(\mathrm{m}^{2} . \mathrm{K}\right)$ e FSo $\leq 6,5 \%$. Mais uma vez, o único valor que não atingiu as recomendações da norma para a cobertura apresentada foi o atraso térmico, que resultou em $6,74 \mathrm{~h}$, enquanto o recomendado era $\varphi \leq 3,3$. A cobertura adotada é a apresentada na Figura 7.

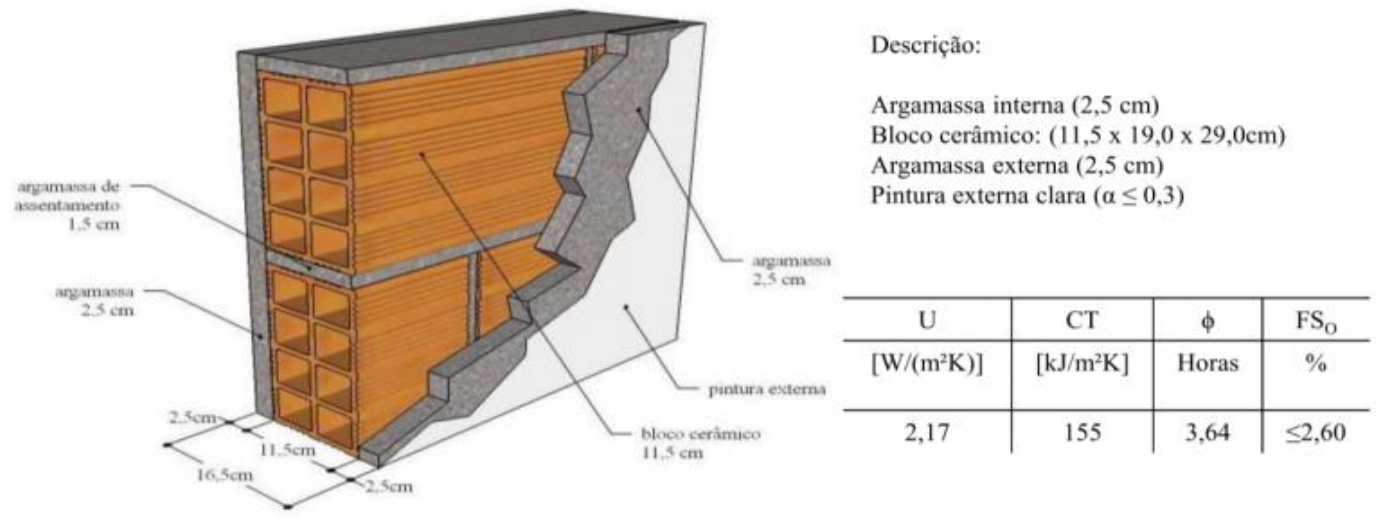

FIGURA 5: Descrição e propriedades de modelo de parede adequado para a ZB6 com bloco 11,5×19,0×29,0cm. FONTE: Autoria própria (2016).

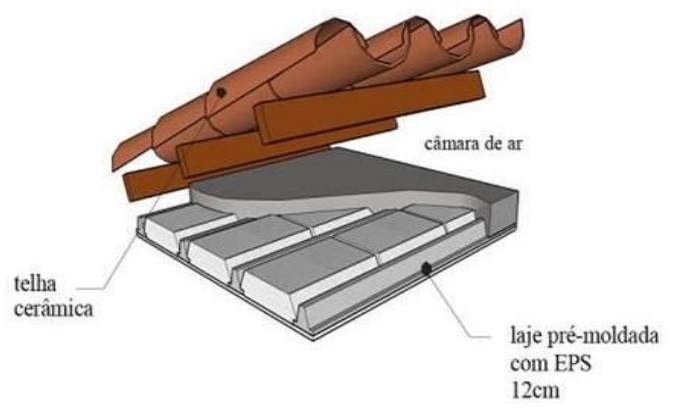

\section{Descrição:}

Laje pré-moldada $12 \mathrm{~cm}$ (concreto $4 \mathrm{~cm}+$ EPS $7 \mathrm{~cm}+$ argamassa $1 \mathrm{~cm}$ ) Câmara de ar $(>5,0 \mathrm{~cm})$ Telha cerâmica

\begin{tabular}{c|c}
\hline$U$ & $C_{T}$ \\
\hline$\left[\mathrm{W} /\left(\mathrm{m}^{2} \mathrm{~K}\right)\right]$ & {$\left[\mathrm{kJ} / \mathrm{m}^{2} \mathrm{~K}\right]$} \\
\hline 1,52 & 150
\end{tabular}

FIGURA 6: Descrição e propriedades do modelo 1 de cobertura adequado para a ZB6. FONTE: INMETRO (2012). 


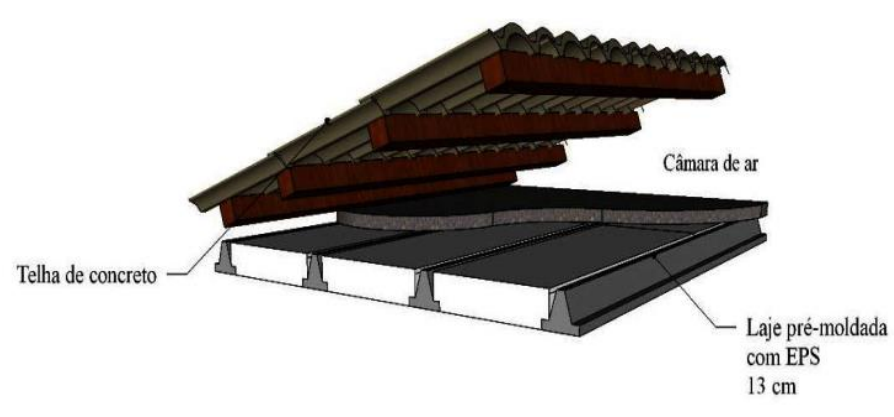

Descrição:

Laje pré-moldada $13 \mathrm{~cm}$ (concreto $4 \mathrm{~cm}+$ EPS $8 \mathrm{~cm}+$ argamassa 1 $\mathrm{cm})$

Câmara de ar $(>5,0 \mathrm{~cm})$

Telha de concreto

\begin{tabular}{c|c|c|c}
\hline $\mathrm{U}$ & $\mathrm{CT}$ & $\phi$ & $\mathrm{FS}_{\mathrm{O}}$ \\
\hline$\left[\mathrm{W} /\left(\mathrm{m}^{2} \mathrm{~K}\right)\right]$ & {$\left[\mathrm{kJ} / \mathrm{m}^{2} \mathrm{~K}\right]$} & Horas & $\%$ \\
\hline 1,06 & 167 & 6,74 & $\leq 3,07$
\end{tabular}

FIGURA 7: Descrição e propriedades do modelo de cobertura utilizado em Catalão e adequado para a ZB6. FONTE: Autoria própria (2016).

\section{TABELA 2: Propriedades térmicas da cobertura comum à cidade de Catalão.}

\begin{tabular}{|c|c|c|c|c|c|c|}
\hline Espessura da telha & 0,010 & $\mathrm{~m}$ & \multirow{3}{*}{ Telha de concreto } & $\rho_{\text {concreto }}$ & 2300 & $\mathrm{~kg} / \mathrm{m}^{3}$ \\
\hline Espessura do concreto & 0,040 & $\mathrm{~m}$ & & $\mathrm{c}_{\text {concreto }}$ & 1,00 & $\mathrm{~kJ} /(\mathrm{kg} . \mathrm{K})$ \\
\hline Espessura do EPS & 0,080 & $\mathrm{~m}$ & & $\lambda_{\text {concreto }}$ & 1,75 & $\mathrm{~W} /(\mathrm{m} \cdot \mathrm{K})$ \\
\hline Espessura da argamassa & 0,010 & $\mathrm{~m}$ & \multirow{3}{*}{ Capa de concreto } & $\rho_{\text {concreto }}$ & 2300 & $\mathrm{~kg} / \mathrm{m}^{3}$ \\
\hline Espessura das vigotas & 0,080 & & & $\mathrm{c}_{\text {concreto }}$ & 1,00 & $\mathrm{~kJ} /(\mathrm{kg} . \mathrm{K})$ \\
\hline Largura EPS & 0,40 & $\mathrm{~m}$ & & $\lambda_{\text {concreto }}$ & 1,75 & $\mathrm{~W} /(\mathrm{m} . \mathrm{K})$ \\
\hline Comprimento EPS & 1,00 & $\mathrm{~m}$ & \multirow{3}{*}{$\begin{array}{l}\text { Preenchimento de } \\
\text { EPS }\end{array}$} & $\rho_{\mathrm{EPS}}$ & 25 & $\mathrm{~kg} / \mathrm{m}^{3}$ \\
\hline Largura vigota & 0,12 & $\mathrm{~m}$ & & $\mathrm{c}_{\mathrm{EPS}}$ & 1,42 & kJ/(kg.K) \\
\hline $\mathrm{Aa}$ & 0,40 & $\mathrm{~m}^{2}$ & & $\lambda_{\mathrm{EPS}}$ & 0,04 & $\mathrm{~W} /(\mathrm{m} . \mathrm{K})$ \\
\hline $\mathrm{Ab}$ & 0,18 & $\mathrm{~m}^{2}$ & \multirow{3}{*}{ Argamassa } & $\rho_{\text {argamassa }}$ & 1950 & $\mathrm{~kg} / \mathrm{m}^{3}$ \\
\hline $\mathrm{R}_{\mathrm{ar}}$ & 0,21 & $\left(\mathrm{~m}^{2} . \mathrm{K}\right) / \mathrm{W}$ & & $c_{\text {argamassa }}$ & 1,00 & $\mathrm{~kJ} /(\mathrm{kg} . \mathrm{K})$ \\
\hline $\mathrm{R}_{\mathrm{si}}$ & 0,17 & $\left(\mathrm{~m}^{2} . \mathrm{K}\right) / \mathrm{W}$ & & $\lambda_{\text {argamassa }}$ & 1,15 & $\mathrm{~W} /(\mathrm{m} . \mathrm{K})$ \\
\hline $\mathrm{R}_{\mathrm{se}}$ & 0,04 & $\left(\mathrm{~m}^{2} . \mathrm{K}\right) / \mathrm{W}$ & & $\alpha$ & 0,725 & Concreto aparente \\
\hline $\mathrm{R}_{\mathrm{a}}$ & 2,25 & $\left(\mathrm{~m}^{2} . \mathrm{K}\right) / \mathrm{W}$ & & & & \\
\hline $\mathrm{R}_{\mathrm{b}}$ & 0,29 & $\left(\mathrm{~m}^{2} . \mathrm{K}\right) / \mathrm{W}$ & & & & \\
\hline $\mathrm{R}_{\mathrm{t}}$ & 0,73 & $\left(\mathrm{~m}^{2} . \mathrm{K}\right) / \mathrm{W}$ & & & & \\
\hline $\mathrm{R}_{\mathrm{T}}$ & 0,94 & $\left(\mathrm{~m}^{2} . \mathrm{K}\right) / \mathrm{W}$ & & & & \\
\hline $\mathrm{U}$ & 1,06 & $\mathrm{~W} /\left(\mathrm{m}^{2} . \mathrm{K}\right)$ & & & & \\
\hline $\mathrm{C}_{\mathrm{Ta}}$ & 137,34 & $\mathrm{~kJ} /\left(\mathrm{m}^{2} . \mathrm{K}\right)$ & & & & \\
\hline $\mathrm{C}_{\mathrm{Tb}}$ & 318,50 & $\mathrm{~kJ} /\left(\mathrm{m}^{2} . \mathrm{K}\right)$ & & & & \\
\hline $\mathrm{C}_{\mathrm{T}}$ & 167 & $\mathrm{~kJ} /\left(\mathrm{m}^{2} . \mathrm{K}\right)$ & & & & \\
\hline$\phi$ & 6,74 & Horas & & & & \\
\hline $\mathrm{FS}_{\mathrm{o}}$ & 3,07 & $\%$ & & & & \\
\hline
\end{tabular}

FONTE: Autoria própria (2016)

Em relação às aberturas, as referências são dadas em relação à área do piso como mostrado no Quadro 5. Vale ressaltar que as aberturas efetivas para ventilação são dadas na norma em percentagem da área de piso para ambientes de longa permanência como cozinha, dormitório, sala de estar, entre outros; logo, para os banheiros e lavanderia não é necessário seguir essa prescrição. 
QUADRO 5: Quadro de pré-requisitos de ventilação conforme várias normativas brasileiras

\begin{tabular}{|c|c|c|}
\hline \multicolumn{2}{|c|}{ Normativa } & A - Área de abertura mínima para ventilação em \% da área do piso \\
\hline \multicolumn{2}{|c|}{ NBR 15220 (ABNT, 2005) } & $15<\mathrm{A}<25$ \\
\hline \multicolumn{2}{|c|}{ NBR 15575 (ABNT, 2013) } & $\geq 7$ \\
\hline \multicolumn{2}{|c|}{ RTQ-R (INMETRO, 2012) } & $\geq 8$ \\
\hline \multirow{3}{*}{$\begin{array}{l}\text { Selo Casa Azul } \\
\text { (CAIXA, 2010) }\end{array}$} & Sala & $\geq 10$ \\
\hline & Dormitórios & \multirow{2}{*}{$\geq 8$} \\
\hline & Cozinhas & \\
\hline
\end{tabular}

FONTE: Autoria própria (2016)

A área de ventilação requisitada pela NBR 15220 (ABNT, 2005) é superior às outras normas, como observado no Quadro 5, mas seria suficiente para satisfazer ao critério de todas, tal que para a ZB6 o ideal é uma ventilação entre $15 \%$ e $25 \%$ da área do piso. Todavia, caso essa prescrição torne o preço da edificação impraticável para os clientes catalanos, assume-se que a prescrição do Selo Casa Azul é aceitável e mais atual.

Ainda em relação à ventilação, destaca-se que somente o RTQ-R possui exigência quanto à ventilação cruzada para a ZB6. Nele está destacado que deve ser proporcionada por sistema de aberturas compreendido pelas aberturas externas e internas, sendo que não são consideradas aberturas para ventilação portas de acesso, principal e de serviço. Para essa ventilação, devem existir aberturas localizadas em pelo menos duas diferentes fachadas (opostas ou adjacentes) e orientações da edificação que promovam condições de escoamento de ar e as aberturas devem atender à proporção da Equação 1:

$$
\frac{A_{2}}{A_{1}} \geq 0,25
$$

Em que:

$\mathbf{A}_{1}=$ somatório das áreas efetivas de aberturas para ventilação localizadas nas fachadas da orientação com maior área de abertura para ventilação $\left(\mathrm{m}^{2}\right)$;

$\mathbf{A}_{\mathbf{2}}=$ somatório das áreas efetivas de aberturas para ventilação localizadas nas fachadas das demais orientações $\left(\mathrm{m}^{2}\right)$.
A NBR 15220 (ABNT, 2005) e o Selo Casa Azul, porém, indicam a ventilação seletiva para o verão. Essa ventilação é ideal para os períodos quentes em que a temperatura interna é superior à externa. Essa estratégia utiliza-se da redução do movimento do ar nos períodos quentes do dia promovendo a captação dos ventos à noite, quando a temperatura do ar é menor e contribuindo para o resfriamento da estrutura (ROMERO, 2000; BATISTA; LAMBERTS; WESTPHAL, 2005).

Logo, é importante que as aberturas estejam voltadas para as direções com predominânciados ventos e sejam passíveis de abrir quando e o quanto o usuário desejar, a fim de proceder com a ventilação seletiva recomendada. No caso de Catalão, estudos realizados na estação 83526 pelo Instituto Nacional de Meteorologia, dos anos de 1961-1990 (INMET, 2010), apontam a direção nordeste como a direção principal de origem dos ventos anuais. Um resultado mais preciso e atualizado da direção e velocidade média desses ventos foi alcançado através de uma análise dos dados históricos do INMET (2015) de 1961 a 2015. A partir desses dados, foi possível a elaboração de dois gráficos com a direção predominante e velocidade média dos ventos em cada mês do ano. O primeiro gráfico apresentado na Figura 8 foi elaborado para os primeiros trinta anos registrados (1961-1990) e o segundo, apresentado na Figura 9, dos últimos 24 anos registrados (1991-2015). 


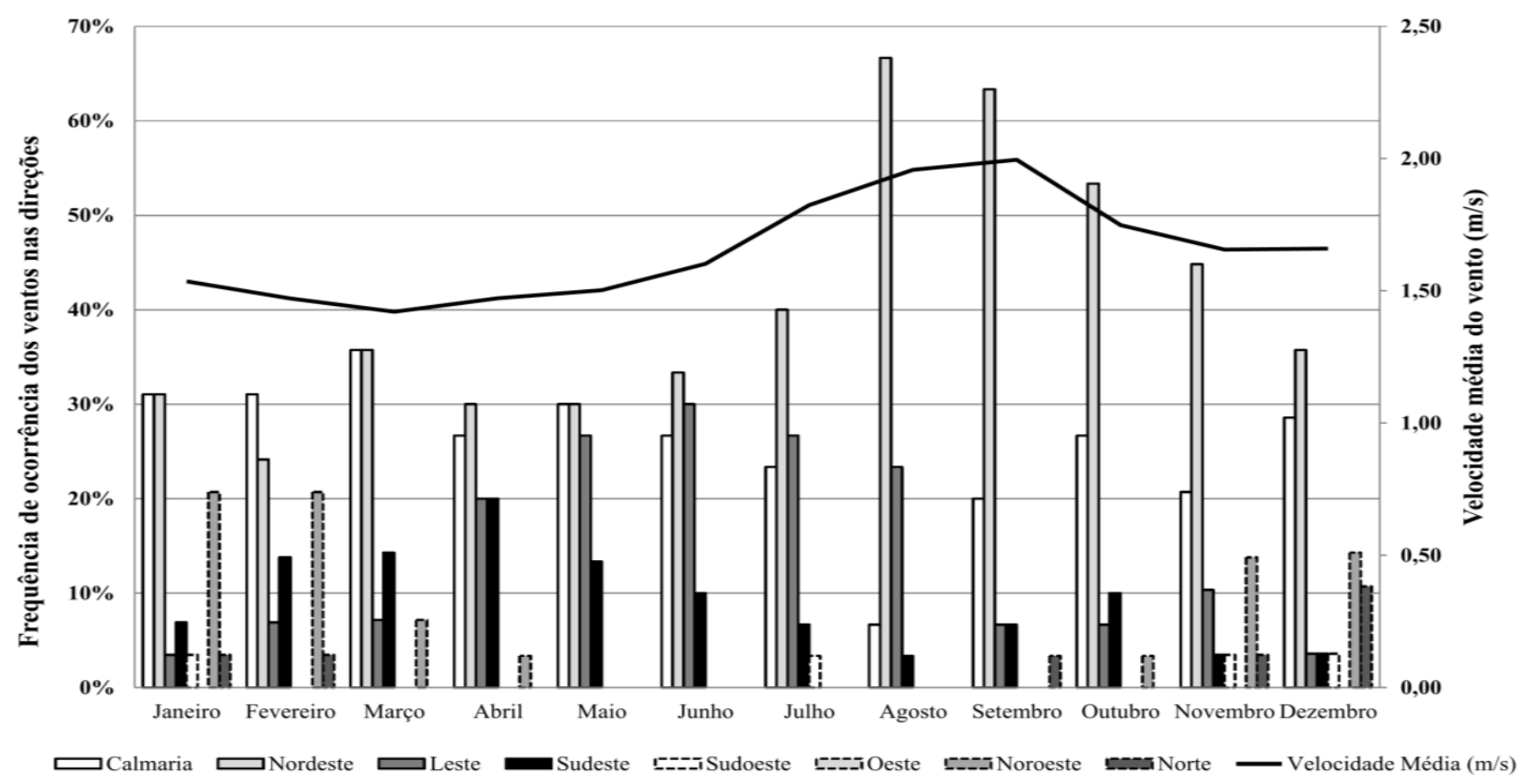

FIGURA 8: Direção predominante e velocidade média dos ventos de janeiro a dezembro de 1961 a 1990. FONTE: Autoria própria (2016).

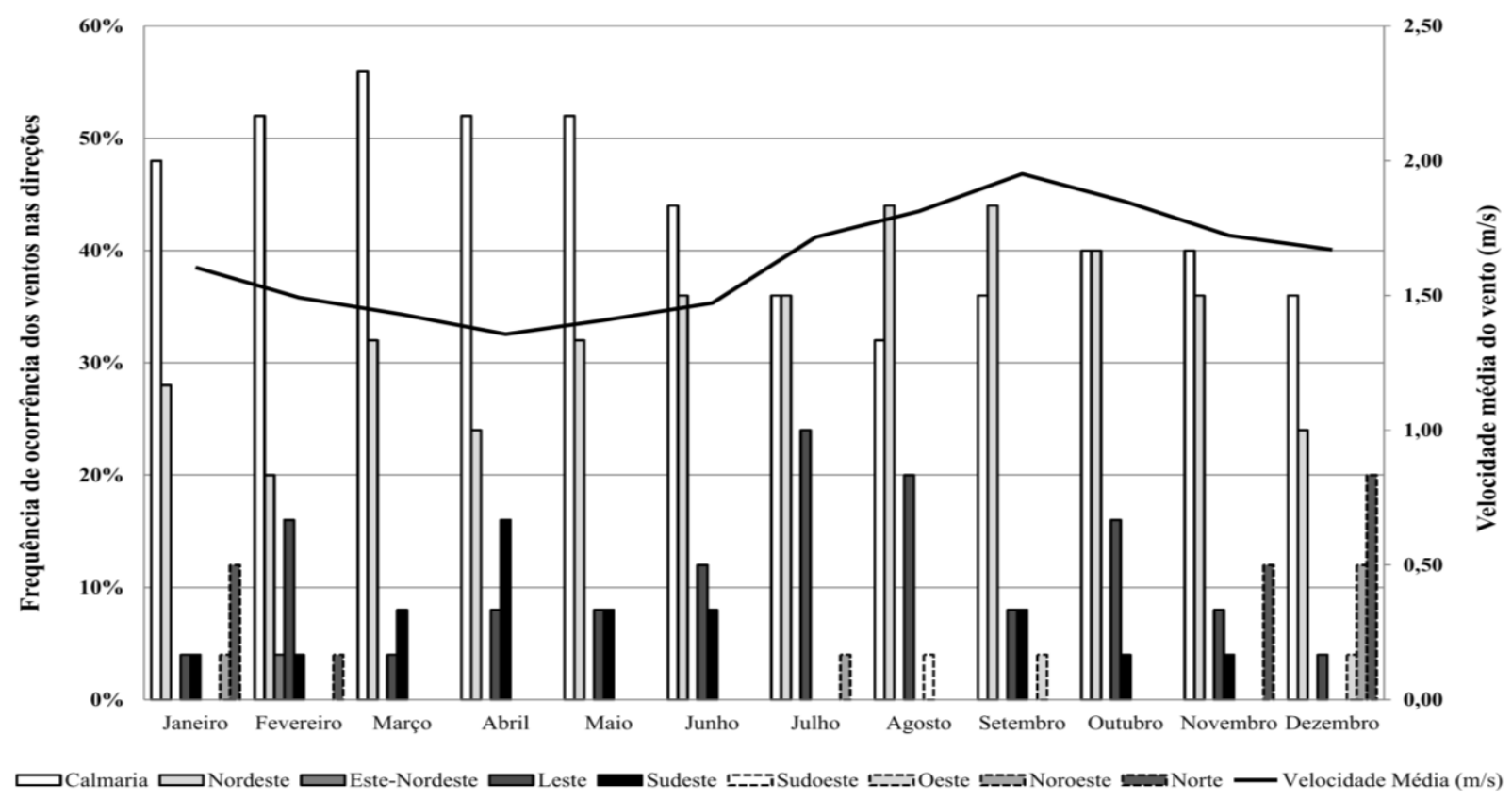

FIGURA 9: Direção predominante e velocidade média dos ventos de janeiro a dezembro de 1991 a 2015. FONTE: Autoria própria (2016).

Ao observar as Figuras 8 e 9 percebe-se que em todos os meses do ano desde 1961, a direção de ventos predominante é a nordeste. $\mathrm{Na}$ Figura 9 nota-se um alto índice de calmaria, pois de 1993 a 1998 só houve registro de calmaria, o que pode significar um período de falta de medições ou algum outro fator que interferiu diretamente nesses anos, mas, mesmo assim não altera o fato de ter a direção nordeste como predominante.
Além disso, por meio dos gráficos apresentados nas as Figuras 8 e 9 percebe-se que as velocidades de vento mais elevadas ocorrem no fim do inverno e início da primavera, predominantemente em setembro. Mediante todas essas observações, para maior ventilação da edificação, as aberturas principais podem ser voltadas para nordeste e suas direções mais próximas: norte e leste. 
Para avaliar as fachadas mais adequadas para as aberturas, além da direção predominante dos ventos, também é importante verificar a insolação que incide nelas devido aos aspectos térmicos e de iluminação natural. Nos gráficos ilustrados nas Figuras 10 e 11 estão apresentados os dados de iluminância máxima no verão e no inverno para auxiliar a análise. Os gráficos foram obtidos com o auxílio do programa DLN (SCARAZZATO, 1997) e são em função da hora solar verdadeira e da iluminância em klx (kilolux). De modo prático, a iluminância é a quantidade de luz em um ambiente, dada pela razão entre o fluxo luminoso, isto é, pela potência de luz total emitida por uma fonte luminosa e a área desse ambiente (CREDER, 2007; PHILIPS, 2010).

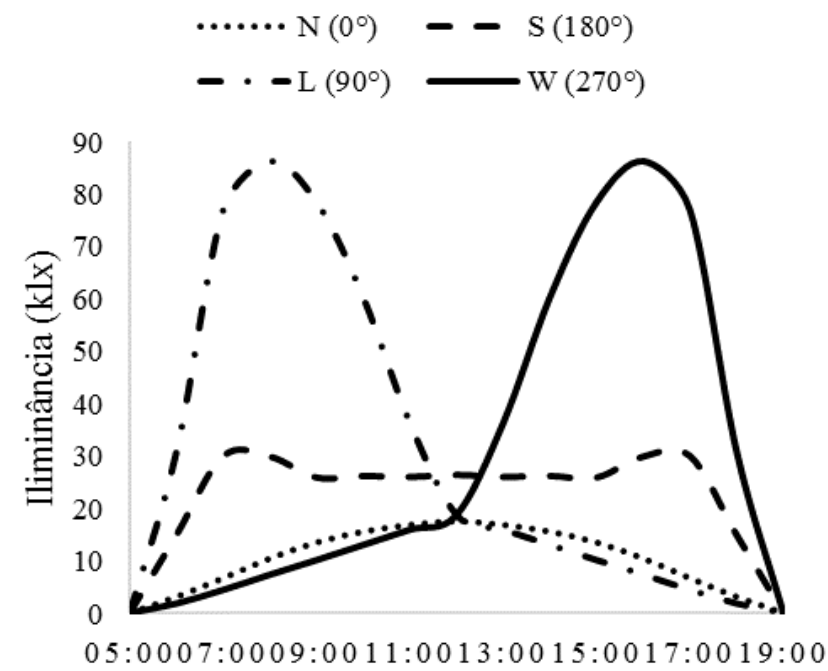

Hora solar verdadeira

FIGURA 10: Iluminâncias máximas no verão (22 de dezembro) em Catalão (GO) para as direções Norte, Sul, Leste e Oeste.

FONTE: Adaptado de Scarazzato (1997).

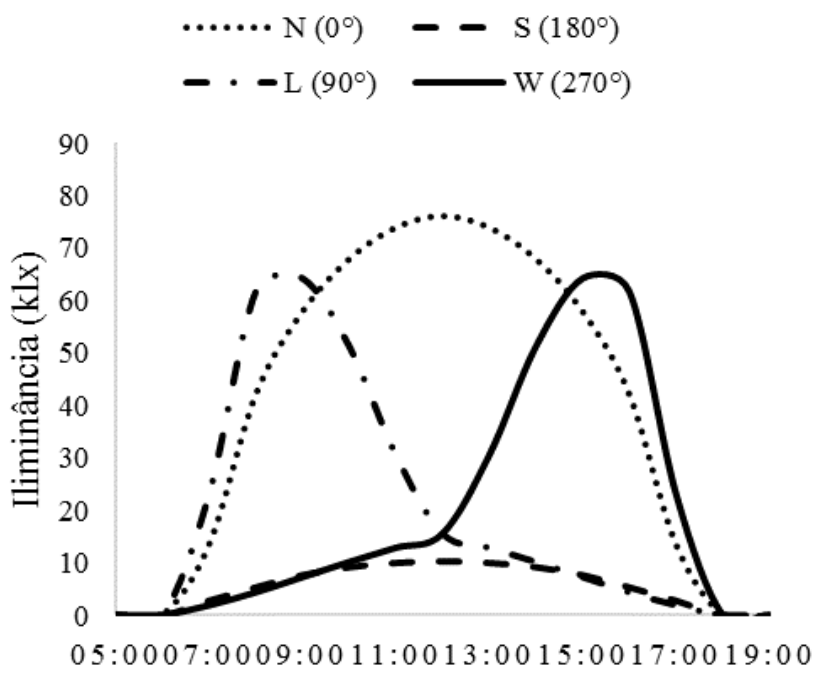

Hora solar verdadeira

FIGURA 11: Iluminâncias máximas no verão (22 de dezembro) em Catalão (GO) para as direções Norte, Sul, Leste e Oeste.

FONTE: Adaptado de Scarazzato (1997). 
Analisando as Figuras 10 e 11 percebe-se que a fachada mais adequada termicamente para as aberturas é a fachada norte, porquanto recebe maior insolação (em termos de intensidade) no inverno e menos no verão (quando o desconforto térmico por calor é maior). A fachada sul recebe pouca incidência solar, e no geral é a que menos recebe o sol ao decorrer do ano, tal que as aberturas voltadas para essa direção também são beneficiadas termicamente, principalmente nos locais quentes. Também é possível perceber nos gráficos apresentados que as fachadas leste e oeste recebem muita radiação solar e para que suas aberturas sejam eficientes devem ser sombreadas.

Se as fachadas norte e leste são beneficiadas em termos de ventilação e as fachadas norte e sul do ponto de vista térmico, entende-se que uma solução seria posicionar as principais aberturas na fachada norte e sul criando uma ventilação cruzada no ambiente para interceptar as aberturas da fachada sul que recebe menos ventilação. E as aberturas na direção leste, que é favorecida pelos ventos, podem ser sombreadas por brises ou outros meios de sombreamento.

Ao avaliar a fachada ideal para abrigar os coletores solares, percebe-se que a fachada norte é a mais adequada. Visto que, nessa orientação há maior recebimento de energia solar ao decorrer de todo o dia sendo a recomendada pela maioria dos estudiosos na área, pois por mais que as fachadas leste e oeste recebam alta insolação é somente durante um período do dia, enquanto a direção norte, por mais que receba quantidades menores no verão, é uma porção suficiente e durante todo o dia. Assis et al. (2007) ainda recomendam que o ideal é planejar uma cobertura de duas águas, em que aquela que não conter os coletores tenha sua maior área voltada para o sul, cuja insolação recebida é menor.

A NBR 15220 ainda apresenta outras diretrizes para o condicionamento térmico passivo para a ZB6, e o Selo Casa Azul reforça essas diretrizes. Dentre as estratégias apresentadas para o verão, são eficientes resfriamento evaporativo,ventilação seletiva e massa térmica para resfriamento;e para o inverno, a utilização de vedações internas pesadas (inércia térmica).

O resfriamento evaporativo é indicado para regiões quentes e secas. Nesse caso, a redução da temperatura pode ser realizada por meio de evaporação, aumentando a umidade do ar (ABNT, 2005; BAGNATI, 2013). Segundo a NBR 15220 (ABNT, 2005), "o resfriamento evaporativo pode ser obtido através do uso de vegetação, fontes de água ou outros recursos que permitam a evaporação da água diretamente no ambiente que se deseja resfriar". Destaca-se a utilização de superfícies gramadas e arborizadas por ser facilmente aplicável e eficiente, uma vez que a vegetação absorve calor utilizando uma parte para a fotossíntese e outra para a evapotranspiração (BAGNATI, 2013).

Santos e Pimentel (2012) ressaltam que nas áreas onde há presença predominante do concreto e do asfalto, as temperaturas tendem a ser mais elevadas e as umidades menores, uma vez que esses elementos retêm e irradiam calor em quantidades consideráveis. Logo, seria importante substituir locais que seriam pavimentados por concreto ou asfalto dentro da edificação por grama ou outra vegetação que melhorariam o resfriamento evaporativo.

Lamberts, Dutra e Pereira (2014) afirmam que na ZB6, as aberturas devem ser sombreadas e se deve evitar a ventilação diurna, já que ela pode aumentar a temperatura interna trazendo ar quente do exterior. Deve-se, então conciliar com a outra diretriz apontada de ventilação seletiva, isto é, no período noturno deve-se permitir a ventilação a fim de retirar o calor acumulado durante o dia, garantindo as temperaturas internas mais baixas no dia seguinte.

A massa térmica pode ser usada tanto para aquecimento quanto para resfriamento. Na ZB6 ela é recomendada para resfriamento. Trata-se de uma estratégia para reduzir a amplitude da temperatura interna em relação à externa, podendo ser alcançada por meio de fechamentos que usem materiais isolantes (BAGNATI, 2013). 
A massa térmica está diretamente relacionada com a inércia térmica. $A$ inércia térmica é a capacidade de uma edificação armazenar calor e liberá-lo certo tempo depois, ou seja, o seu princípio baseia-se na teoria que o calor armazenado na estrutura da edificação durante o dia é devolvido à noite, quando as temperaturas externas diminuem e a estrutura resfriada a noite mantém-se fria durante a maior parte do dia, reduzindo as temperaturas do ambiente interno nos dois períodos. A relação fica estabelecida, uma vez que o calor que é retido no interior de uma edificação, ao ser conduzido de um extremo a outro, é consequência da massa térmica que quanto maior, mais calor armazena no material (DORNELLES, 2004; BAGNATI, 2013; LAMBERTS; DUTRA; PEREIRA, 2014)

A inércia térmica provoca a redução das amplitudes, através do amortecimento $(\mu)$ das temperaturas internas e da defasagem (Atraso térmico - $\varphi$ ) delas em relação às temperaturas externas, logo, é necessária ser maior em regiões com altas variações da temperatura externa, radiação solar e ganhos de calor (DORNELLES, 2004). As vedações internas pesadas seguem o mesmo princípio, garantindo maior inércia térmica inclusive para o ambiente interno.

\section{CONCLUSÕES}

Conforme análise da NBR 15220 (ABNT, 2005), verificou-se que a cidade de Catalão está inserida na ZB6 e tanto a NBR 15220 (ABNT, 2005), quanto a NBR 15575 (ABNT, 2013), o RTQ-R e o Selo Casa Azul apresentaram diretrizes para essa zona, possibilitando verificar a coincidência de algumas recomendações assim como divergências. Logo, buscou-se considerar que as adequadas eram aquelas que atendiam a todas ou que eram mais atuais. Além de se atentar para as prescrições das normas, foram feitas adequações às preferências do consumidor de Catalão.

Constatou-se que em Catalão é utilizado principalmente vedações com blocos cerâmicos de $11,5 \times 19,0 \times 29,0 \mathrm{~cm}$ e coberturas de telhas de cimento e lajes pré-moldadas TG 8 com enchimento de EPS. Esses elementos atenderam a todos os requisitos das propriedades térmicas para a ZB6, com exceção do atraso térmico, que para ser atendido iria contra os componentes mais aceitos no mercado catalano.

O trabalho contribui identificando as características necessárias a um projeto arquitetônico, que atende a bioclimatologia, possibilitando maior eficiência energética para a ZB6, com destaque à cidade de Catalão e região. Foram identificadas as melhores orientações solares para as fachadas, direção predominante do vento e ventilações a serem facilitadas, tamanhos das aberturas, propriedades das vedações e coberturas, entre outras estratégias de condicionamento térmico.

\section{REFERÊNCIAS BIBLIOGRÁFICAS}

ABNT - ASSOCIAÇÃO BRASILEIRA DE NORMAS TÉCNICAS. NBR ISO 15220 - Desempenho térmico de edificações. Rio de Janeiro, 2005.

ABNT - ASSOCIAÇÃO BRASILEIRA DE NORMAS TÉCNICAS. NBR ISO 15575 - Edificações habitacionais Desempenho. Rio de Janeiro, 2013.

ASHRAE 55 - AMERICAN SOCIETY OF HEATING REFRIGERATING AND AIR CONDITIONING ENGINEERS. Thermal environmental conditions for human occupancy. Atlanta, 2013. 54 p.

ASSIS, E. S.; PEREIRA, E. M. D.; SOUZA, R. V. G.; DINIZ, A. S. A. C. Habitação social e eficiência energética: um protótipo para o clima de Belo Horizonte. In: Congresso Brasileiro de Eficiência Energética, 2., 2007, Vitória. Anais... Vitória: II CBEE, 2007, p. 1-7.

BAGNATI, M. M. Zoneamento bioclimático e arquitetura brasileira: Qualidade do ambiente construído. 2013. 133 f. Dissertação (Mestrado em Arquitetura) - Programa de Pesquisa e Pós-Graduação em Arquitetura, Universidade Federal do Rio Grande do Sul. Porto Alegre, 2013

BATISTA, J. O.; LAMBERTS, R.; WESTPHAL, F. S. Avaliação de desempenho térmico de componentes construtivos utilizando o ENERGYPLUS. In: Encontro Nacional de Conforto no Ambiente Construído (ENCAC)/ (IV Encontro Latinoamericano/ ELACAC), 8 , 2005, Maceió. Anais... Maceió: ANTAC, 2005.p. 145-154.

CAIXA. Selo casa azul. 2010. Disponível em: <http://www.caixa.gov.br/sustentabilidade/produtosservicos/selo-casa-azul/Paginas/default.aspx> Acesso em: 24 ago. 2015. 
CREDER, H. Instalações elétricas. 15 ed. Rio de Janeiro: LTC, 2007. 914 p.

DEGANI, C. M.; CARDOSO, F. F. A sustentabilidade ao longo do ciclo de vida de edifícios: a importância da etapa de projeto arquitetônico. In: Seminário Internacional de Sustentabilidade, Arquitetura e Desenho Urbano, 2002, São Paulo. Anais... São Paulo: NUTAU/ USP - Núcleo de Pesquisa em Tecnologia da Arquitetura e Urbanismo da Faculdade de Arquitetura e Urbanismo da Universidade de São Paulo, 2002.

DORNELLES, K. A. Estudo de casos sobre a inércia térmica

de edificações na cidade de São Carlos, SP. 2004, 148 f. Dissertação(Mestrado em Construção Civil) -Programa de Pós-Graduação em Construção Civil, Universidade Federal de São Carlos. São Carlos, 2004.

GONÇALVES, J. C. S.; DUARTE, D. H. S. Arquitetura sustentável: umaintegração entre ambiente, projeto etecnologia em experiências depesquisa, prática e ensino. Ambiente construído, v. 6, n. 4, p. 51-81, 2006.

GOUVÊA, T. C. Avaliação do conforto térmico: uma experiência na indústria da confecção. 2004. $149 \mathrm{f}$. Dissertação (Mestrado em Engenharia Civil) -Faculdade de Engenharia Civil, Arquitetura e Urbanismo, Universidade Estadual de Campinas.Campinas, 2004.

HUANG, K. T., HUANG, W. P., LIN, T. P., HWANG, R. L. Implementation of green building specification credits for better thermal conditions in naturally ventilated school buildings. Building and Environment, v. 86, p. 141-150, 2015.

INMET - INSTITUTO NACIONAL DE METEOROLOGIA. Dados históricos. 2015. Disponível em: <http://www.inmet.gov.br/portal/index.php?r=bdmep/ bdmep> Acesso em: 29 out. 2015

INMET - INSTITUTO NACIONAL DE METEOROLOGIA. Normais climatológicas do Brasil 1961 - 1990. 2010. Disponível em: <http://www.inmet.gov.br/portal/index.php?r=clima/N ORMAISCLIMATOLOGICAS> Acesso em: 04 out. 2015

INMETRO - INSTITUTO NACIONAL DE METROLOGIA, QUALIDADE

$E$

TECNOLOGIA. Portaria $\mathrm{n}^{\circ}$ 18, de 16 de janeiro de 2012: Regulamento Técnico da Qualidade para o Nível de Eficiência Energética de Edificações Residenciais. Rio de Janeiro, 2012. Disponível em: <http://www.inmetro.gov.br/legislacao/rtac/pdf/RTACO 01788.pdf> Acesso em: 19 set. 2015

INMETRO - INSTITUTO NACIONAL DE METROLOGIA, QUALIDADE

TECNOLOGIA. Portaria $n^{\circ} \mathbf{5 0}$, de 01 de fevereiro de 2013: Requisitos de avaliação da conformidade para eficiência energética de edificações. Rio de Janeiro, 2013.

Disponível <http://www.pbeedifica.com.br/sites/default/files/proje tos/etiquetagem/RTAC001961.pdf $>$ Acessoem: 04 nov. 2015

ISO - INTERNATIONAL ORGANIZATION FOR STANDARDIZATION.ISO 7730: Ergonomics of thethermal environment - Analytical determination and interpretation of thermal comfort using calculation of the PMV and PPD indices and local thermal comfort criteria. Geneva, 2005.

JAMES, A. D.; CHRISTIAN, K. An assessment of thermal comfort in a warm and humid school building at Accra, Ghana. Advances in Applied Science Research, v. 3, n. 1, p. 535-547, 2012.

KAPPAUN, K. Avaliação do desempenho térmico em edificações de blocos estruturais cerâmicos e de blocos estruturais de concreto para a zona bioclimática 2 brasileira. 2012. 125 f. Dissertação (Mestrado em Engenharia Civil) - Programa de Pós-Graduação em Engenharia Civil e Ambiental, Área de Concentração em Construção Civil e Preservação Ambiental, Universidade Federal de Santa Maria. Santa Maria, 2012.

LAMBERTS, R.; DUTRA, L.; PEREIRA, F. O. R. Eficiência energética na arquitetura. 3 ed. Rio de Janeiro: Eletrobrás PROCEL, 2014, 366 p. Disponível gratuitamente

<http://www.mme.gov.br/documents/10584/198

5241/Livro\%20-

\%20Efici\%C3\%AAncia\%20Energ\%C3\%A9tica\%20na\%20A rquitetura.pdf>. Acesso em: 15 jun. 2015.

LAMBERTS, R.; TRIANA, M. A. Levantamento do estado da arte: Energia. Documento 2.2. Projeto Tecnologias para construção habitacional mais sustentável. São Paulo: FINEP, 2007. 94 p.

LAMBERTS, R.; XAVIER, A. A. P. Conforto térmico e stress térmico. Florianópolis: laBEE - Laboratório de Eficiência Energética em Edificações de Santa Catarina, 2002. 110 p.

PHILIPS. Technical data. 2010. Disponível em: <http://www.ribaproductselector.com/

Docs/9/05799/external/COL2205799.pdf> Acesso em: 03 dez. 2015

PROCEL INFO - CENTRO BRASILEIRO DE INFORMAÇÃO DE EFICIÊNCIA ENERGÉTICA. Selo Procel Edificações. Disponível em: <http://www.procelinfo.com.br/> Acesso em: 23 nov. 2015

ROMERO, M. A. B. Princípios bioclimáticos para o desenho urbano. Brasília: CopyMarket.com, 2000. 63 p.

SANTOS, F. O.; PIMENTEL, M. R. S. Edificações e conforto térmico: a moradia como fonte de aprendizagem. Caminhos da geografia, v. 13, n. 44, p. 265-285, 2012.

SCARAZZATO, P. S. DLN - Cálculo de Disponibilidade de Luz Natural. Versão 2.06. 1997. Labaut - Laboratório de 
Conforto Ambiental e Eficiência Energética, Faculdade de Arquitetura e Urbanismo, Universidade de São Paulo. Disponível

em: <http://www.fau.usp.br/pesquisa/laboratorios/labaut/c onforto/index.html> Acesso em: 23 ago. 2015. 